\title{
Effect of integrated yoga module for anger management on heart rate variability in high school children-a pilot study
}

\begin{abstract}
Aim: Total population in the coming years is majorly going to be adolescents. Adolescents are challenged with a number of stressors and peer pressure at home and school. 'Anger' is an emotion which leads adolescents to substance abuse, violence, aggression, accidents and many more. There are very few studies done on the health, wellbeing of Indian adolescents. This study was mainly aimed to understand anger, its Physiological arousal, and whether HRV can be a good indicator to study anger, using integrated yoga module.
\end{abstract}

Materials and methods: A pre-and post-study was conducted in high school with yoga as an intervention. Yoga sessions were conducted during school hours for one month with weekly five sessions of forty minutes each. Data was collected using Bio-nomadix logger before the intervention and a month later after the intervention.

Conclusion: There was significant reduction of sympathetic tone in yoga group. Vagal tone increased in yoga group whereas it decreased in controlled group.
Volume II Issue 6 - 2018

\author{
Sumana NS,' Alaka mani TL,' Sudheer \\ Deshpande ${ }^{2}$ \\ 'Research Scholar, S-VYASA University, India \\ ${ }^{2}$ Joint Director, S-VYASA University, India
}

Correspondence: Sumana NS, Research Scholar, S-VYASA University, India, Email sumanavenay123@gmail.com

Received: December 18, 2017| Published: December 04, 2018

\section{Introduction}

The heart rate can vary according to the body's physical needs. During dynamic exercise, the heart rate increases as the rate of work increases. Physical exercises, sleep, anxiety, stress, illness and ingestion of drugs beats Per Minute increased during negative emotions like anger and fear whereas was constant during positive emotions like happiness. Emotions influence the beat-to-beat fluctuations. Other factors which influence on this are hormones, notably epinephrine, nor epinephrine, thyroid hormones and many more. Release of the hormones epinephrine from the adrenal medulla of the adrenal glands is part of the fight and flight response. The sympathetic nervous system is described as being complementary to the parasympathetic nervous system which stimulate the body to "feed and breed" and then "rest and digest". Cardiac parasympathetic activity was assessed using Electro Cardio Gram (ECG) which gives complete and valid sensitive way of monitoring cardiac-parasympathetic activity. ${ }^{1-5}$

Low HR is a marker of resilience to the effects of environmental challenges in early adolescence. In adults, physical exercise has beneficial effect on autonomic control of the heart, with decreased resting heart rate often accompanied with increase in HRV. Iyengar yoga increases cardiac parasympathetic nervous modulation among healthy adults. The increase in HRV parameter was significantly higher during yoga exercise and had control over the vagal tone.

During puberty, maximal heart rate decreases with age are a rate of 0.7 or 0.8 beats per minute/year of age. Females have a higher heart rate than males at any given ate of work after puberty. High HRV is correlated with increased self-regulatory capacity, emotional regulation, sense of coherence, and self-directedness, as well as improved social interactions and effective coping styles. Studies on premenstrual syndrome in adolescent girls reported high prevalence (59\%) of anger irritability as most common symptom. Slow abdominal breathing was taught to the intervention group and nothing was given to the control group. HRV biofeedback training contributes to the beneficial effect of reducing the stress related cardiovascular response in pre-hypertensive. School based yoga programs may be appropriate for promoting healthy behavior at a societal level by focusing on the prevention of negative patterns during the adolescent transition. ${ }^{6-10}$

Application of yoga in the field of education in secondary schools is considered feasible and acceptable. Yoga subject is made mandatory in CBSE schools. The National Curriculum Framework (NCF) adopted a holistic definition of health, in which yoga is an integral part (NCERT 2011). Increased awareness, viability and popularity of yoga in schools provide strong grounds to explore efficacy of yoga education to address anger issues in children. IAYT or IYM is a holistic yoga model which prescribes yogic techniques for each for these koshas. Yogic techniques in IAYT include all 8 components of Astanga Yoga (Yama, Niyama, Asana, Pranayama, Pratyahara, Dharana, Dhyana \& Samadhi), Karma Yoga, Bhakti Yoga, Jnana Yoga, Kriya (Cleansing techniques) and yogic diet. ${ }^{11-15}$

According to traditional Indian scripture 'adolescents' is marked by the term 'Brahmacharya' in the age group of 8 to 20 years. The important point is to focus during this stage is to build a disciplined and value based culture. Adolescence (bramacharya) is the right age to impart moral education or develop positive virtues to overcome anger through the life span. A bramchari's life is to only obey the guru and learn all essential teachings Vedas, Upanishads, puranas, Vedic scriptures and many more. Adolescents in the fit of anger get into such situation which leads them to substance abuse, unwanted speed leading to road accidents, depression, low self-esteem - which leads to suicidal attempt. This is the major social problem facing in the modern society/which has to be addressed.

Panchakosha viveka explains, on Adhi's which originates in Manomaya kosha and also percolates into another kosha. Adhi corresponds to modern psychosomatic ailments. When the mind is agitated during the interactions with the world at large, the physical body also follows in its wake. These agitations cause violent fluctuations in the flow of prana in the nadis. This fluctuation in the flow of prana is expressed as disease in later years. In Yoga Vasista it is said that childhood is a state of helplessness. Youth is a period of 
arrogance, and slavery of lust. Old age is described as treated with contempt even by the family members. In yoga Vasista the essence of yoga is beautifully portrayed. ${ }^{16-20}$

\section{Manah prashamanopayah yoga ityabhidhiyate}

Yoga is called a skilful trick to calm down the mind, it is an "upayaha", meaning a trick or a technique to calm the mind and bring us to tranquility.

\section{Tapahsvadhyayayesvarapranidhanani kriyayoghah, Tapas, swadhyaya, ishwara pranidhana constitute kriya yoga}

Self-restraints(Yamas), fixed rules(Niyamas), postures(Asana), breath control(Pranayama), sense withdrawal (prathyahara), concentration(Dhyana), meditation(Dharana), Liberation(samadhi) are the eight parts of yoga discipline. Heart rate values always fluctuate under the influence of number of factors and particularly when emotionally aroused. Heart rate increases especially during Anger, Beats per Minute increases during negative emotions like anger and fear whereas were constant during positive emotions like happiness. Emotions influence the beat-to-beat fluctuations. Release of the hormones epinephrine from the adrenal medulla of the adrenal glands is part of the fight and flight response.

Cardiac parasympathetic activity was assessed using Electro Cardio Gram(ECG) which gives complete and valid sensitive way of monitoring cardiac-parasympathetic activity. Iyengar yoga increases cardiac parasympathetic nervous modulation among healthy adults. The increase in HRV parameter was suggestively higher during yoga exercise and had control over the vagal tone. High frequency HRV states the depressive symptoms among adolescents. Typically, researches are concerned with the baseline vagal tone, treating it either as a potential predictor of behavior or examining its relationship with mental health (particularly emotion regulation, MDD, Anxiety and Internalizing and externalizing disorders). School based yoga programs may be appropriate for promoting healthy behavior at a societal level by focusing on the prevention of negative patterns during the adolescent transition. ${ }^{21-26}$

\section{Aim and objectives}

\section{Aim}

Effect of yoga in high school children on anger by studying the physiological and psychological parameters

\section{Objectives}

To study the changes in Heart Rate Variability in high school children practicing yoga for anger management.

\section{Hypotheses}

Yoga intervention will bring changes in HRV parameters in adolescents in experimental group when compared to the control group.

\section{Null-hypotheses}

Yoga intervention will not bring any changes in HRV parameters in adolescents in experimental group when compare to the control group.

\section{Design of study}

A stratified randomized control pre - post experimental / intervention research is chosen for the study. A study plan is done to conduct yoga classes for 5 days in a week in with one period i.e. 40 $\min$ per day.

\section{Inclusion criteria}

Students studying in $8^{\text {th }}$ standard section 'A' were taken as control group and section 'B' as yoga intervention group. Students who were able to read, write and communicate in English were taken for the study. Boys and girls who were willing to participate were taken for the study. Students belonging to the same age group and who had same body mass index (BMI) were taken. Boys and girls who were healthy and sound were taken for the study. ${ }^{27-30}$

\section{Exclusion criteria}

Students who had health problems, disabilities, slow learners and children who needed special attention were not taken. Boys and girls who did not belong to the same age group were excluded. Children who already practiced yoga were not included in the study. Students who were not interested to participate were not included. Students whose parents did not give the consent were also not included.

\section{Ethical consideration}

Consent to participate in the survey was obtained in writing by the children and approval obtained from school authorities. Authorized tools and software were used for measurements and assessment. Girls were advised to come in appropriate attire. Students who were unwell were allowed to rest.

\section{Sample size}

Sampling size will be 53 students. 33 students belong to intervention and another 20 students belonging to control group.

\section{Participants}

High school children studying in $8^{\text {th }}$ STD section A \& B from jnana sagar English medium school.

\section{Sampling technique}

It is convenient sampling belonging to south Bangalore, we searched and selected a school, the school arranged two sections, 'Class $8^{\text {th }}$, 'A' for control and ' $\mathrm{B}$ ' for intervention. Jnana sagara English medium school gave us the permission to conduct the intervention. The School authorities were very co-operative, provided all the requirements for the intervention. One free period was allotted which was of 40 minutes duration. Every day we made sure we carried a first-aid box with us. The students were enthusiastic, waited for the class every day. Though there were few who gave excuses. Yoga intervention was given during the academic hours \& yoga intervention was carried out only during school hours. Duration and time for the yoga intervention was given 5 days in a week for a month in a given period of 40 minutes per day as allotted by the school authority.

\section{Independent variable, dependent variable, heart rate variability (HRV)}

While doing HRV analysis, it is important to distinguish situations where the subject is breathing normally. When monitoring or assessing 
subject's HRV spontaneously physiological patterns are seen naturally. When doing HRV biofeedback, you are decisively changing the subject's natural state to exercise specific physiological factors of HRV. The interpretation of the various HRV metrics differs in both these states. Unless specified otherwise, the following descriptions apply only to situations where the client is breathing normally (Table 1)..$^{31-35}$

Table I Yoga Module for Anger Management in Adolescents-Session

\begin{tabular}{|c|c|c|c|c|}
\hline SI No & & & Source & Time \\
\hline I & & Opening prayer & Baghavad Gita Ch 2, verse $62 \& 63$ & $3 \mathrm{~min}$ \\
\hline \multirow[t]{12}{*}{2} & Asanas \& Postures & Dynamic series & & $10 \mathrm{~min}$ \\
\hline & & Shashankasana & & \\
\hline & & Bhujangasana & & \\
\hline & & Adhomukha swanasana & & \\
\hline & & $\begin{array}{l}\text { Suryanamasakara Balancing \& forward } \\
\text { bending posture }\end{array}$ & & \\
\hline & & & 10 steps type & \\
\hline & & Triyaka tadasana & & \\
\hline & & Ostrich pose & & \\
\hline & & Standingb vrikshasana & & \\
\hline & & Veera bhadrasana-3 & & \\
\hline & & Natarajasana & & \\
\hline & & Paschimottanasana & & \\
\hline \multirow[t]{4}{*}{3} & Pranayama & Conscious breathing & & $5 \mathrm{~min}$ \\
\hline & & Abdominal breathing & & \\
\hline & & Alternate nostril breathing & & \\
\hline & & Brahmari pranayama & & \\
\hline 4 & Meditation & $\begin{array}{l}\text { Modified version of MEMT (Mastering } \\
\text { emotion Technique) }\end{array}$ & Developed by Svyasa & $15 \mathrm{~min}$ \\
\hline \multirow[t]{8}{*}{5} & Jnana Yoga & Physiology Psychology & & $5 \mathrm{~min}$ \\
\hline & & Screening of short films on Anger & & \\
\hline & & Yogic concepts & & \\
\hline & & & Ahimsa, Brahmacharya & \\
\hline & & & Santosha,Swadhyaya & \\
\hline & & & Ishwara Pranidhana & \\
\hline & & Food \& Anger & Pratyahara & \\
\hline & & Moral stories on Anger & & \\
\hline 6 & & Closing prayer & Baghavad Gita Ch 3 Verse 37 & $2 \min$ \\
\hline
\end{tabular}


The various HRV metrics fall into two broad categories: time domain and frequency domain. Time domain in the time domain we find all the mathematical processes that analyze a series of IBI values gathered over time. These include statistical calculations, such as mean and standard deviation, and a few very specialized calculations. Key time domain metrics include: SDRR (or SDNN): This metric looks at how much variability exists during a given period of time. It is the standard deviation of IBI values calculated over a minute, usually. Since the standard deviation is a representation of how spread-out the IBI values are, higher SDRR values represent greater variability.

Note that, RR stands for " $\mathrm{R}$ to R" and means "beat to beat". The $\mathrm{R}$ refers to the $\mathrm{R}$ spike of an EKG signal because EKG is the signal of choice for doing HRV research. NN means "normal to normal"; this nomenclature is specifically used to qualify a series of IBI values which has been cleaned of any artifacts (normalized). ${ }^{36-42}$

\section{Data extraction}

Data was collected during the school using bio-nomadix logger. An attempt was made to measure the above physiological parameters at resting state, in school. Raw Data was collected before and after one month's yoga intervention. The data was collected from the 8th std students of two sections A and B. There were some hurdles faced by us

a. Some girls were exempted due to their Menstrual cycle.

b. Non-availability of both pre-and post-data (children who were absent, sick)

c. Errors which were done regarding the tying of the sensors (loose or tight) d. Lack of time, as the exams were approaching the authorities asked us to hasten the process.

The bio-signals studied in HRV were (sympathetic tone, vagal tone and sympathetic- vagal balance)

Procedure: As a pilot work, the scale was first administered to 30 children to assess the feasibility; content was read out to them to make understand certain words and sentences, so that they could write the required correctly. Children were briefed out about the study and then asked to fill the questionnaire correctly. From the review of published papers, it is understood that the physiological parameters with specific reference to anger is not studied and more so with the adolescents. Hence a pilot work is carried out to study Heart rate variability (HRV)

Bio-nomadix logger: This is a portable wireless device which records bio-signals accurately by just mounting the sensors on the skin (noninvasive). It consists of a matched transmitter and receiver specifically optimized for desired physiological signals. At a time, it can record 6 bio signals. Disposable, self-jelled and adhesive electrodes are needed to measure HRV and Skin conductance. HRV -53 were the subjects where 33 were of yoga group, and 20 were of control group. The recorded data in the logger was first imported to computer. Each and every student was designated a logger number. The inbuilt software which gives the data in the excel sheet form. This analysis had to be done for parameter, separately and for each data collected pre-and post per child separately. Pre-and post-analysis of data for both yoga and control group was carried using paired t-test and the results are tabulated (Table 2)(Table 3)(Table 4)(Figure 1). ${ }^{43-46}$

Table 2 Pre-and post-analysis of data for both yoga and control group was carried using paired t-test and the results are tabulated

\begin{tabular}{lllllll}
\hline Yoga group & Mean & $\mathbf{N}$ & Std. deviation & Std. error mean & Sig. (2-tailed) \\
\hline Pair I & Pre-Sympathetic tone & 0.608 & 33 & 0.17 & 0.03 & 0.009 \\
& Post Sympathetic tone & 0.515 & 33 & 0.17 & 0.03 & \\
Pair 2 & Pre-Vagal tone & 0.44 & 33 & 0.161 & 0.028 & 0.73 \\
& Post HRVVagal tone & 0.453 & 33 & 0.18 & 0.031 & 0.564 \\
Pair 3 & Pre-Sympathetic vagal balance & 1.827 & 33 & 1.828 & 0.318 & \\
& Post sympathetic vagal balance & 1.626 & 33 & 1.273 & 0.222 & \\
\hline
\end{tabular}

Table 3 Pre-and post-analysis of data for HRV Control Group was carried using paired t-test and the results are tabulated

\begin{tabular}{lllllll}
\hline $\begin{array}{l}\text { HRV control } \\
\text { group }\end{array}$ & & Mean & $\mathbf{N}$ & Std. deviation & $\begin{array}{l}\text { Std. error } \\
\text { mean }\end{array}$ & Sig. (2-tailed) \\
\hline Pair I & Pre-Sympathetic tone & 0.575 & 20 & 0.1492 & 0.7334 & 0.161 \\
& Post Sympathetic tone & 0.632 & 20 & 0.1712 & 0.0383 & 0.062 \\
Pair 2 & Pre-Vagal tone & 0.446 & 20 & 0.1857 & 0.0415 & 0.728 \\
& Post Vagal tone & 0.372 & 20 & 0.1609 & 0.036 & 0.3326 \\
Pair 3 & Pre-Sympathetic vagal balance & 2.14 & 20 & 1.4876 & 0.3254 & \\
& Post-Sympathetic vagal balance & 2.012 & 20 & 1.4554 & & \\
\hline
\end{tabular}


Table 4 Significance of HRVYoga Control Group

\begin{tabular}{llll}
\hline Significance (2 Tailed) & & HRV yoga group & HRV control group \\
\hline Pair I & Sympathetic Tone & 0.009 & 0.161 \\
Pair 2 & Vagal Tone & 0.73 & 0.062 \\
Pair 3 & Sympathetic Vagal Balance & 0.564 & 0.728 \\
\hline
\end{tabular}

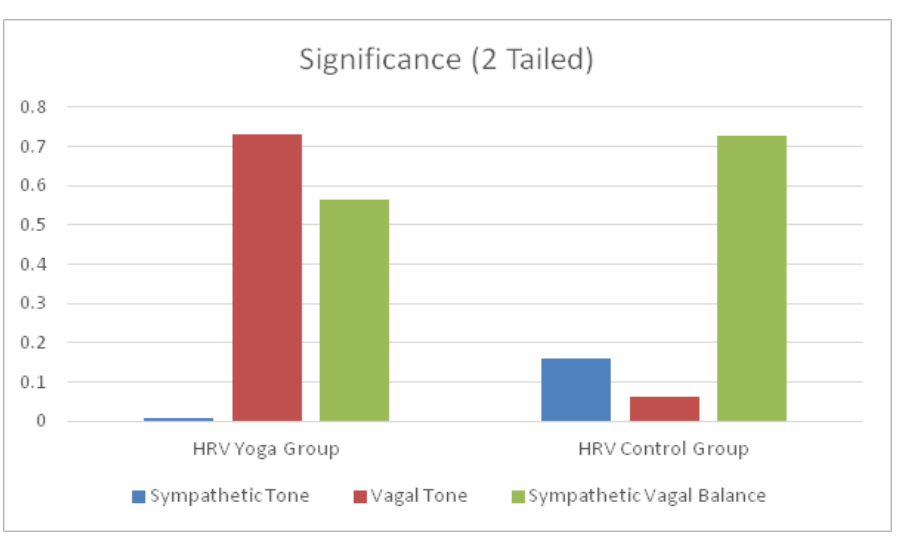

Figure I Significance of HRVYoga and Control group.

\section{Results}

There was a significant reduction of sympathetic tone in yoga group. However, mean data shows reduction in sympathetic tone in yoga group and increase in sympathetic tone in control group. Similarly, vagal tone has increased in yoga group and decreased in control group. Both the groups have shown reduction in sympathetic - vagal balance this indicates yoga program was effective in reducing the sympathetic arousal and increasing the parasympathetic (vagal) activities. $^{47-50}$

\section{Conclusion}

Yoga Intervention for anger management was effective in increasing of sympathetic tone in Yoga Group and decrease in sympathetic tone in control group. Yoga group showed increase in vagal tone and control group showed decreased vagal tone. This indicates that the physiological parameter-Heart Rate Variability (HRV) is sensitive to emotions such as anger. ${ }^{51}$

\section{Discussion}

The pilot study to examine the changes in HRV parameters due to a yoga intervention for anger management in high school children has produced promising results. This indicates that HRV could be considered as a bio-marker for anger. Since this is the first of its kind study. The goal of this study was to understand whether did the school children benefit in the reduction of anger or understand the concept of anger and its effect after attending the yoga intervention. The parameter HRV was used to detect weather there is any sympathetic arousal.

\section{Confounding factors}

There are many questions which arise in this study whether this study really brought changes in the children. Whether yoga is really helpful? There were some places where actually we had no clue about the students: Their lifestyle, their diet, their locality and surroundings, their upbringing, their interests which also matters for the study. Keeping in mind for the future study on students (adolescents), the effect of yoga and the HRV

\section{Strengths}

a. We learnt how to give interventions, how to collect data, and how to convert the data into excel sheet.

b. During the study there were many other concepts which we learnt, (svadhyaya)

c. We learnt more than we taught, the students showed lot of interest which boosted our interests too. There was a healthy competition between boys and girls.

d. Students who were unwell and were absent were not included in the data and so we lost some of the data.

\section{Weaknesses}

If the raw signal you are recording contains too much artefact, artefact is patterns in the signals that are not created by the physiological process of interest. Artefacts happen when the signal gets distorted by movement or other sources of noise. Artefacts cause errors in the signal processing calculations and make the data analysis unreliable.

a. Missed beats and Extra beats, both types are most often caused by signal distortion.

b. It is important to mention that there are also real natural physiological events, premature atrial or ventricular contraction (PAC or PVC) will engender oddball IBI values which disturb the frequency domain calculations and should be corrected.

c. Electrode movement artefact.

d. Students who were unwell, girls who had MC, and injuries or burns were excluded.

e. We were short of time and were not allowed to take the reading from the children or correct the artefact as the school had given a limited time schedule for intervention.

\section{Acknowledgments}

None.

\section{Conflicts of interest}

Author declares that there is no conflicts of interest. 


\section{References}

1. Kim KH, Bang W, Kim SR. Emotion recognition system using short monitoring of physiological signals. Medical and Biological Engineering and computing. 2004;42:419-427.

2. Pawłowska B, Potembska E, Zygo M, et al. Prevalence of selfinjury performed by adolescents aged 16-19 years. Psychiatry Pol. 2016;50(1);29-42.

3. Henje Blom E, Olsson EM, Serlachius E, et al. Heart rate variability is related to self-reported physical activity in a healthy adolescent population. Eur J Appl physiol. 2009;106:877-833.

4. Telles S. Effect of Yoga on Mental Health in children, editor, Child and Adolescent Mental Health. New Delhi; Sage Publications; 2012. p. 219-227.

5. Alaka Mani TL, Sharma MK, Omkar SN, et al. Holistic Assessment of Anger in adolescents using KayenaVacha and Manasa conceptDevelopment of a rating scale. JAyurveda Integr Med. 2018;9(3):195-200.

6. Schoorl J, Rijn S, Wied M. Neurobiological stress responses predict aggression in boys with oppositional defiant disorder/conduct disorder; a 1-year follow-up intervention study. Eur Child Adolesc Psychiatry. 2017;26(7):805-813.

7. Hagglund KJ, Clay DL, Frank RG. Assessing anger in children and adolescents. J Pediatr Psychol. 1994;19(3):291-304.

8. Raymond Di Giuseppe, Michal Barnea, Gabriella Duke, et al. Evidence based assessment and intervention for anger in school psychology. Handbook of Australian School of phycology. 2017. p. 349-376.

9. Aysin B, Aysin E. Effect of respiration in heat rate variability analysis. Conf Proc IEEE Eng Med Biol Soc. 2006;1:1776-1779.

10. Montano N, Porta A, Cogliati C, et al. Heart rate variability explored in the frequency domain: a tool to investigate the link between heart and behavior. Neurosci Biobehav Rev. 2009;33(2):71-80.

11. Hendricks V, Sam B, Dean A, Guy M. The Effect of Anger on the Brain and Body National Forum Journal of Counseling and Addiction. National Forum Journal of Counseling and Addiction. 2013;2(1):1-11.

12. Kristin AG. The effectiveness of school-based anger interventions and programs; a meta-analysis. Journal of School Psychology. 2005;43(4):321-324.

13. Chaya MS, Nagendra H, Selvam S, et al. Effect of Yoga on cognitive abilities in schoolchildren from a socio economically Disadvantaged Background: A Randomized controlled study. J Altern Complement Med. 2012;18(12):1-7.

14. Huesmann LR, Eron LD, Dubow EF. Childhood predictors of adult criminality; are all risk factors reflected in childhood aggressiveness? Criminal Behaviour and Metal Health. 2002;12(3):185-208.

15. Kaley Isley LC, Peterson J, Fischer C, et al. Yoga as a complementary therapy for children and adolescents-A Guide for Clinicians; Psychiatry (Edgemont). 2010;7(8):20-32.

16. BhideAV.Anger and Mahabharata. Indian JPsychiatry. 2007;49:140-142.

17. Miers AC, Rieffe C, Meerum Terwogt M. The relation between Anger coping Strategies', Anger mood and somatic complaints in children and adolescents. J abnorm child psychol. 2007;35:653-664.

18. Cheng H, Yun jin Y, Xue Song Y. An emotion Recognition System Based on Physiological Signals Obtained by Wearable Sensors. Wearable Sensors and Robots. 2017;399:15-25.

19. Quinn CA, Rollock D, Vrana SR. A Test of Spielberger's State- Trait
Theory of Anger with Adolescents: Five hypotheses. Emotion. 2014;14(1):74-84.

20. Hubbard JA, Meghan DM, Ronnie MR, et al. The Anger-Aggression Relation in Violent Children and Adolescents. Book chapter; 2006.

21. Spielberger. State-Trait Anger Expression Inventory (STAXI) Professional manual. Lutz FL: Psychological Assessment Resources; 1988.

22. Telles S. Shirley Telles, Effect of Yoga on Mental Health in children. Child and Adolescent Mental Health. New Delhi; Sage Publications; 2012. p. 219-227.

23. Eva Henje Bom, Erik M Golssan, Eva Serlachius, et al. Heart rate variability is related to self-reported physical activity in a healthy adolescent population. Eur J Applphysiol. 2009;106(6):877-883.

24. Pawłowska B, Potembska E, Zygo M, et al. Prevalence of self-injury performed by adolescents aged 16-19 years. Psychiatry Pol. 50(1);29-42.

25. Brunner TM, Spielberger CD. The State Trait Anger Expression Inventory, Child Adolescent. STAXI-C/A. Florid: Professional Manual, Psychological Assessment Resources; 2009.

26. Hendricks La Velle, Sam Bore, Dean Aslinia, et al. The Effect of Anger on the Brain and Body. National Forum Journal of Counseling and Addiction. 2013;2(1).

27. Herrman DS, Mc Whirter JJ. Anger and aggression management in young adolescents an experimental validation of the SCARE program. Education and treatment of children. 2003;26(3):273-302.

28. John A. Photo plethysmography and its application in clinical physiological measurement. Physiol Meas. 2007;28(3):R1-R39.

29. Khalsa SB, Hickey-Schultz L, Cohen D, et al. Evaluation of the Mental Health Benefits of Yoga in a Secondary School; A Preliminary Randomized Controlled Trial. J Behav Health Serv Res. 2012;39(1):80-90.

30. Lehrer P. Anger, stress, dysregulation produces wear and tear on the lung; Editorial, Anger and Lung Function, Thorax 2006;61(10):833-834.

31. Lisa A Conboy, Jessica JN, Jessica LF, et al. Qualitative Evaluation of a high school yoga program; feasibility and perceived benefits. Explore. 2013;9(3):171-180.

32. Lisa CK, John Peterson, Colleen Fischer, et al. Yoga as a complementary therapy for children and adolescents-A Guide for Clinicians. Psychiatry (Edgemont). 2010;7(8):20-32.

33. Galantino ML, Galbavy R, Quinn L. Therapeutic Effects of Yoga for Children; A Systematic Review of the Literature. Pediatr Phys Ther. 2008;20(1):66-80.

34. Bhutkar MV, Bhutkar PM, Taware GB, et al. How effective is Sun Salutation in improving Muscle Strength, General Body Endurance and Body Composition? Asian J Sports Med. 2011;2(4):259-266.

35. Pierre Philippot, Gaetane Chapelle, SlvieBlairy. Respiratory feedback in generation of emotion; Article in Cognition and Emotion. Journal of Cognition and Emotion. 2010.

36. Rosalind WP, EliazV, Jennifer H. Towards Machine Emotional Intelligence - Analysis of affective physiological state. Cambridge: Technical Report No.536 of MIT Media Laboratory; 2001.

37. Society of Neurosciences.

38. RIMMI. Book-Series for Children (Volume 1 to 5). Mumbai: Published by Ramamanilyengar Memorial Yoga Institute, Pune and Yoga; 2012.

39. SVYASA. Krida Yoga book series. Published by Vivekananda Kendra Prakashan Trust. 2009 
40. Washington RL, Bricker JT, Alpert BS, et al. Guidelines for Exercise testing in the Paediatric Age Group; Committee on Atherosclerosis and hypertension in the young; The American Heart Association. Circulation. 1994;90(4):2166-2179.

41. Vazquez L, Blood JD, Wu J, et al. High frequency heart-rate variability predicts adolescent depressive symptoms, particularly anhedonia, across one year. 2016;15(196):243-247.

42. Lehrer PM, Vaschillo E, Vaschillo B, et al. Heart rate variability biofeedback increases baroreflex gain and peak expiratory flow. Psychosom Med. 2003;65(5):796-805.

43. Dwivedi U, Kumari S, Nagendra HR. Effect of yoga in reducing counterproductive work behavior and its predictors. Indian J Psychaitry. 2016;58(2):216-219

44. Narasimhan L, Nagarathna R, Nagendra H. Effect of integrated yogic Practices on positive and negative emotions in healthy adults. Int $J$ Yoga. 2011;4(1):13-9.

45. Zarshenas L, Baneshi M, Sharif F, et al. Anger management in substance abuse based on cognitive behavioral therapy. BMC Psychiatry. 2017;17(1):375
46. Ramaprasad D. Emotions: An Indian perspective; Indian journal of psychiatry. Indian J Psychiatry. 2013;55(S 2):S153-S156.

47. Swati NC, Santhosh KA, Anand K. Feature Normalization for Enhancing Early detection of Cardiac Disorders.

48. Sivagurunathan C, Umadevi R, Rama R, et al. Adolescent Health: Present status and its related programs in India. Are we in the right direction? $J$ Clin Diagn Res. 2015;9(3):LE01-LE06.

49. Hasmukh A, Nagendra HR. Impact of adoption of yoga way of life on the emotional intelligence of managers. IIMB Management Review. 2010;22(1-2):32-41.

50. Oldehinkel AJ, Verhulst FC, Ormel J. Low heart rate; a marker of stress resilience. The trial study. Biol Psychiatry. 2008;15;63(12):1141-1146.

51. Jorgensen RS, Johnson BT, Kolodziej ME, et al. Elevated blood pressure and personality: a meta-analytic review. Psychol Bull. 1996;120(2):293-320. 